\title{
Liquid Metal Cooled Reactors
}

\author{
Peter Wydler*
}

\begin{abstract}
The long-term vision of a sustainable nuclear energy system is an important driver for the development of fast reactors because, apart from generating energy, these can serve as fuel-producing factories or transuranic waste burners. This key role in advanced fuel cycles and new, innovative applications have revived the interest in various alternative fast reactor concepts such as liquid heavy metal and gas-cooled systems which, in the longer term, are perceived to have some advantages over the conventional sodium-cooled fast reactors. This article focuses on the liquid metal cooled reactors. After a brief history of these reactors, the advantages and drawbacks of different liquid metal coolants are overviewed and, in the second part, current development trends are summarised, following the lines of the recent US initiative for a technology roadmap for Generation IV nuclear energy systems.
\end{abstract}

Keywords: Fast reactors · Generation IV systems · Liquid metal coolants

\section{A Brief History of Liquid Metal Cooled Reactors}

The possibility of building a fast neutron reactor which is able to produce more fissile material than it consumes was discussed by E. Fermi and W.H. Zinn already in 1944. At Los Alamos, Fermi's ideas led to the construction of the mercury-cooled fast reactor Clementine which reached criticality in 1946; at Argonne, Zinn started to develop a fast reactor concept which later became known as Experimental Breeder Reactor I (EBR-I). The sodium-potassium cooled EBR-I reached criticality in 1951 and was the first nuclear reactor in the world to generate electricity [1]. Similar Russian and British developments resulted in the construction of the sodium-potassium cooled reactors BR-2 at Obninsk (1956) and DFR at Dounreay (1959). All these reactors used early types of metal alloy fuels which had a limited burnup capability and were therefore not suited for commercial application.

*Correspondence: Dr. P. Wydler

Huttenacherstr. 12

$\mathrm{CH}-5452$ Oberrohrdor

Tel.: +41564963574

c/o Paul Scherrer Institut

$\mathrm{CH}-5232$ Villigen PSI

Tel.: +41563102067

E-Mail: peter.wydler@psi.ch
A second generation of fast reactors was launched in 1959 with the Russian BR-5. Common to this generation are the sodium coolant and the fuel in the form of enriched uranium oxide and/or mixed uranium-plutonium oxide (MOX). The oxide allowed the fuel burnup to be increased to around $10 \%$ and hence the fuel cycle cost to be reduced. In the following, a series of experimental test reactors based on this concept, with thermal powers in the range 20 to $400 \mathrm{MW}$, were put into operation in France, Germany, Japan, Russia, the USA, and India. From 1972, France, Japan, the former USSR and the UK proceeded to the construction and operation of prototype reactors in the power range 150 to $280 \mathrm{MWe}$, of which Phénix in France (first criticality in 1973) and Monju in Japan (first criticality in 1994) are still operating. Large (preindustrial) demonstration plants went critical in Russia (1980) and in France (1985). While the Russian BN-600 (600 MWe) is still operating, the French/German/Italian Superphénix (1240 MWe) was finally shut down in 1996 after various technical difficulties which resulted in increased public and political opposition against this type of plant.

Increasing difficulties with the funding of national fast reactor programmes and the lessons learnt from the joint Superphénix venture, in 1988, led to the establishment of the European Fast Reactor (EFR) collaboration which was aimed at combining the best features of the national projects. The collaboration was pursued for ten years and resulted in a reference design with considerable flexibility in the fuel cycle. The EFR is representative for the current generation of large, monolithic plants. Thanks to this collaboration and similar efforts in Japan, the sodium-cooled, MOX-fuelled fast reactor concept has reached a greater maturity than any other fast reactor concept.

Currently, one observes a revival of metal alloy fuelled fast reactor concepts, especially for smaller plants. A breakthrough in the development of the metal alloy fuel was achieved with the Integral Fast Reactor (IFR) initiative in the USA which is based on a fuel consisting of a ternary alloy of uranium, plutonium, and zirconium. As could be demonstrated in EBR-II, such fuels have excellent steady-state and transient performance and can sustain a peak burnup up to $20 \%$. The concept was launched by Argonne National Laboratory in 1984 and resulted in different plant designs. However, the work came to a halt in 1994 when the US government decided to terminate the IFR programme.

\section{Fast Reactor Coolants}

\subsection{Comparison of Liquid Metals with Gases and Water}

The principal fast reactor coolants considered today are liquid metals and gases (helium and $\mathrm{CO}_{2}$ ). If breeding is not required, water can also be used as a coolant. $\mathrm{H}_{2} \mathrm{O}$-steam cooled and $\mathrm{D}_{2} \mathrm{O}$-steam cooled fast reactor concepts were studied in Germany and the USA between 1960 and 1970 , but then abandoned for technical reasons. Concepts for supercritical-water cooled systems, however, were recently revived in the form of a fast-spectrum variant of the supercritical-water cooled reactor (SCWR) 
Table 1. Properties of fast reactor coolants

\begin{tabular}{|c|c|c|c|}
\hline Property & $\begin{array}{l}\text { Liquid metals } \\
\text { ( } \mathrm{Na}, \mathrm{Pb}-. \mathrm{Bi}, \mathrm{Pb} \text { ) }\end{array}$ & Gas $\left(\mathrm{He}, \mathrm{CO}_{2}\right)$ & Water \\
\hline Neutronic properties & good & excellent & poor \\
\hline $\begin{array}{l}\text { Heat transfer } \\
\text { properties }\end{array}$ & excellent & $\begin{array}{l}\text { good (at high } \\
\text { pressure) }\end{array}$ & good \\
\hline $\begin{array}{l}\text { Core outlet } \\
\text { temperature }\end{array}$ & $\begin{array}{l}\sim 550{ }^{\circ} \mathrm{C} \text {, } \\
\text { up to } 800^{\circ} \mathrm{C} \text { for } \mathrm{Pb}\end{array}$ & $850^{\circ} \mathrm{C}$ for GFR & $510^{\circ} \mathrm{C}$ for SCWR \\
\hline Pressure & $\begin{array}{l}\text { low } \\
\text { ( atmospheric) }\end{array}$ & $\begin{array}{l}\text { high } \\
\text { (9 MPa for GFR) }\end{array}$ & $\begin{array}{l}\text { very high } \\
\text { ( } 25 \mathrm{MPa} \text { for SCWR) }\end{array}$ \\
\hline Thermal inertia & large & small & medium \\
\hline Transparency & opaque & transparent & transparent \\
\hline $\begin{array}{l}\text { Chemical interaction } \\
\text { potential }\end{array}$ & $\begin{array}{l}\text { Na reacts with water } \\
\text { and air }\end{array}$ & inert & \\
\hline Corrosion potential & $\begin{array}{l}\text { low for } \mathrm{Na} \text {, significant } \\
\text { for } \mathrm{Pb} \text { and } \mathrm{Pb}-\mathrm{Bi}\end{array}$ & $\begin{array}{l}\mathrm{CO}_{2} \text { requires } \\
\text { corrosion control }\end{array}$ & $\begin{array}{l}\text { requires water } \\
\text { chemistry control }\end{array}$ \\
\hline Activation & $\begin{array}{l}\mathrm{Na} \text { is activated } \\
\mathrm{Pb}-\mathrm{Bi} \text { forms }{ }^{210} \mathrm{Po}\end{array}$ & & $\begin{array}{l}\text { corrosion products } \\
\text { are activated }\end{array}$ \\
\hline
\end{tabular}

considered in the framework of the Generation IV initiative. $\mathrm{N}_{2} \mathrm{O}_{4}$ has been studied in Russia, and molten salts have been investigated by various groups in the USA, Russia, and Japan. Table 1 compares the important properties of liquid metals, gases, and water.

The neutronic properties are important for the breeding and/or transmutation potential of the reactor. Thanks to the absence of neutron moderation and absorption, Helium offers the best performance in this respect. Another neutronic advantage of the gas is that it avoids the positive coolant void reactivity effect which is a safety concern particularly in sodium-cooled fast reactors. (A positive void reactivity effect means increased reactor power in the event of coolant boiling.) The moderation of the neutrons by liquid metals 'softens' the neutron spectrum and thereby somewhat reduces the breeding potential. If a high power density is not essential, the low neutron absorption of the lead facilitates opening the lattice of fuel pins without a significant loss in the neutron economy and thus opens the way to innovations which can increase passive safety and reduce cost. Water has the disadvantage of high neutron moderation and absorption which makes the design of water-cooled breeder reactors difficult, if not impossible. Such concepts may, however, still find applications as actinide burners.

The excellent heat transfer properties of liquid metals strongly influenced the coolant choice for the first generation of fast reactors. At that time, a short fuel doubling time was assumed to be essential for a viable fast reactor concept. A short fuel doubling time, however, implies a high power density in the reactor core which can best be achieved with a liquid metal coolant. To ensure a good heat transfer, gas-cooled reactors have to be operated at high pressure and coolant velocity which imply high pumping power.

The coolant outlet temperature has to be judged with regard to the mission of the reactor. For an electricity producer, the outlet temperature of about $550{ }^{\circ} \mathrm{C}$ for a conventional liquid metal cooled reactor is more than satisfactory. Compared with a conventional light water reactor (LWR), it offers a better steam quality and an improvement in the electrical efficiency of about $30 \%$. The interest in high-temperature process applications for fast reactors is relatively new (In the past, such applications were assigned to high-temperature reactors with a thermal neutron spectrum). Provided that the required high-temperature materials can be developed, lead-cooled and helium-cooled fast reactors could reach outlet temperatures of $800{ }^{\circ} \mathrm{C}$ and more. Whereas helium is favoured for large plants, lead has advantages for smaller-size plants.

The coolant pressure and the thermal inertia of the reactor core influence the safety characteristics of the reactor. A high pressure increases the potential for loss-ofcoolant accidents and, in combination with a low thermal inertia, can lead to rapid core melting. The thermal inertia of a gas-cooled fast reactor core is small because neither the coolant nor a moderator can buffer the heat. This means that small disturbances in the core can initiate fast transients which can only be controlled with active safety systems. By contrast, liquid metal cooled cores have a considerable passive safety po- tential as loss-of-cooling accidents can be ruled out and, thanks to the thermal inertia, the cores can be designed such that negative reactivity feedbacks from the structures stabilise the core.

The passive safety advantages of the liquid metals compared with gas have to be weighted against some disadvantages of the liquid metals that affect operation and maintenance. For example, the opacity of the liquid metals implies the development of special inspection techniques. The activation of the coolant and the chemical interaction potential call for the provision of special components $e . g$. an intermediate heat transport system and a double-walled reactor vessel. Finally, the limited compatibility of some liquid metals with steel necessitates the installation of suitable corrosion control systems. While $\mathrm{CO}_{2}$ may require gas chemistry and corrosion control, helium is not affected by any of these problems. However, a common operational drawback of gases is that the high coolant flow rates induce dynamic loads and hence vibration and noise.

For the first fast reactors with high power density and metal-fuelled cores, liquid metal coolants were the obvious choice. Helium was considered in connection with the switch from metal to oxide fuel which led to a reduction in the power density of the core. Helium-cooled fast reactor concepts were studied in Europe, the former USSR, and the USA mainly as a back-up for the sodium-cooled fast reactor. However, as yet no helium-cooled fast test or demonstration reactor has been built. After liquid metal cooling had proved to be feasible also for larger cores, it was generally agreed that it is to be preferred on account of its passive safety advantages. More recently, however, some countries including France and the USA have started to revisit the gas-cooled fast reactor concept.

\subsection{Which Liquid Metal Coolant?}

Sodium, sodium-potassium (NaK), mercury, lead, and lead-bismuth (Pb-Bi), usually in the form of lead-bismuth eutectic (LBE), have been considered as coolants. Mercury, which was used in the first fast reactor, is not suited for large-scale application, but still finds applications as a target coolant, e.g. for spallation neutron sources. $\mathrm{NaK}$ was used in early fast reactor designs because of its low melting point - as mercury, it is liquid at room temperature - but was later discarded because the potassium absorbs too many neutrons. Lead and $\mathrm{Pb}-\mathrm{Bi}$ were initially also discarded for civil applications because their high density implies a high pumping power and complicates the design [2]. However, $\mathrm{Pb}-\mathrm{Bi}$ was used in Russia as a coolant for submarine reactors. More recently, the interest in lead and $\mathrm{Pb}-\mathrm{Bi}$ as a coolant has been revived in connection 
with innovative applications such as actinide transmutation, hydrogen production, and power generation in remote areas.

Table 2 provides the melting temperature $\left(\mathrm{T}_{\mathrm{m}}\right)$, the boiling temperature $\left(\mathrm{T}_{\mathrm{b}}\right)$, the specific heat at constant pressure $\left(c_{p}\right)$ and the thermal conductivity $(\mathrm{k})$ for the liquid metals which are currently under consideration as coolants. In the past, sodium was the favoured coolant because it has a low melting temperature while preserving an adequate margin to boiling and is superior in all other parameters.

A switch from sodium to lead or $\mathrm{Pb}-\mathrm{Bi}$ has been proposed mainly for safety reasons:

- Hot liquid lead and $\mathrm{Pb}-\mathrm{Bi}$ do not react violently with air (sodium fires have been perceived as an important problem of sodium-cooled reactors although, for a properly designed plant, they present more an operational than a safety threat).

- Lead- and Pb-Bi-cooled fast reactor cores have a smaller positive void reactivity effect than sodium-cooled cores (The positive void reactivity effect is a much-criticised feature of large sodiumcooled cores as it provides a mechanism for a prompt-critical power excursion which can lead to a whole core accident).

- The very high margin to boiling of lead and $\mathrm{Pb}-\mathrm{Bi}$ reduces the probability of boiling-induced accidents (in leadcooled reactors, however, this advantage may be nullified by the increased freezing risk [3]).

- In the primary coolant circuit of leadand $\mathrm{Pb}-\mathrm{Bi}$-cooled reactors, the (active) pumps can be replaced by a natural circulation system to enhance the passive safety of the core [4][5]. (In sodiumcooled reactors, natural convection is applied in auxiliary decay heat removal systems, but is not suited for heat removal at full power.)

- In the event of a hypothetical fuel melting accident, frozen lead may provide an effective barrier against radiation and a radioactivity release.

The most important, safety relevant disadvantage of lead and $\mathrm{Pb}-\mathrm{Bi}$ is their inclination to erosion and corrosion in contact with steel. Whereas sodium is practically free from such problems, the limited compatibility of lead and $\mathrm{Pb}-\mathrm{Bi}$ with steel may jeopardise important reactor functions. In combination with the poor inspectability of liquid metal cooled systems, this could pose significant safety problems, e.g. structural failures and blockages by sludge. The current approach to master the problem is to ensure that the steel surfaces are always protected by an oxide layer. Special oxygen control techniques will be required to keep the oxygen
Table 2. Heat transfer data for sodium, lead and lead-bismuth

\begin{tabular}{lllc} 
Property & Sodium & Lead & Lead-bismuth (LBE) \\
\hline $\mathrm{T}_{\mathrm{m}}\left[{ }^{\circ} \mathrm{C}\right]$ & 98 & 328 & 123 \\
$\mathrm{~T}_{\mathrm{b}}\left[{ }^{\circ} \mathrm{C}\right]$ & 880 & 1743 & 1670 \\
$\mathrm{C}_{\mathrm{p}}\left[\mathrm{kJ} / \mathrm{kg}-{ }^{\circ} \mathrm{C}\right]$ & 1.3 & 0.14 & 0.15 \\
$\mathrm{k}\left[\mathrm{W} / \mathrm{m}-{ }^{\circ} \mathrm{C}\right]$ & 75 & 14 & 13
\end{tabular}

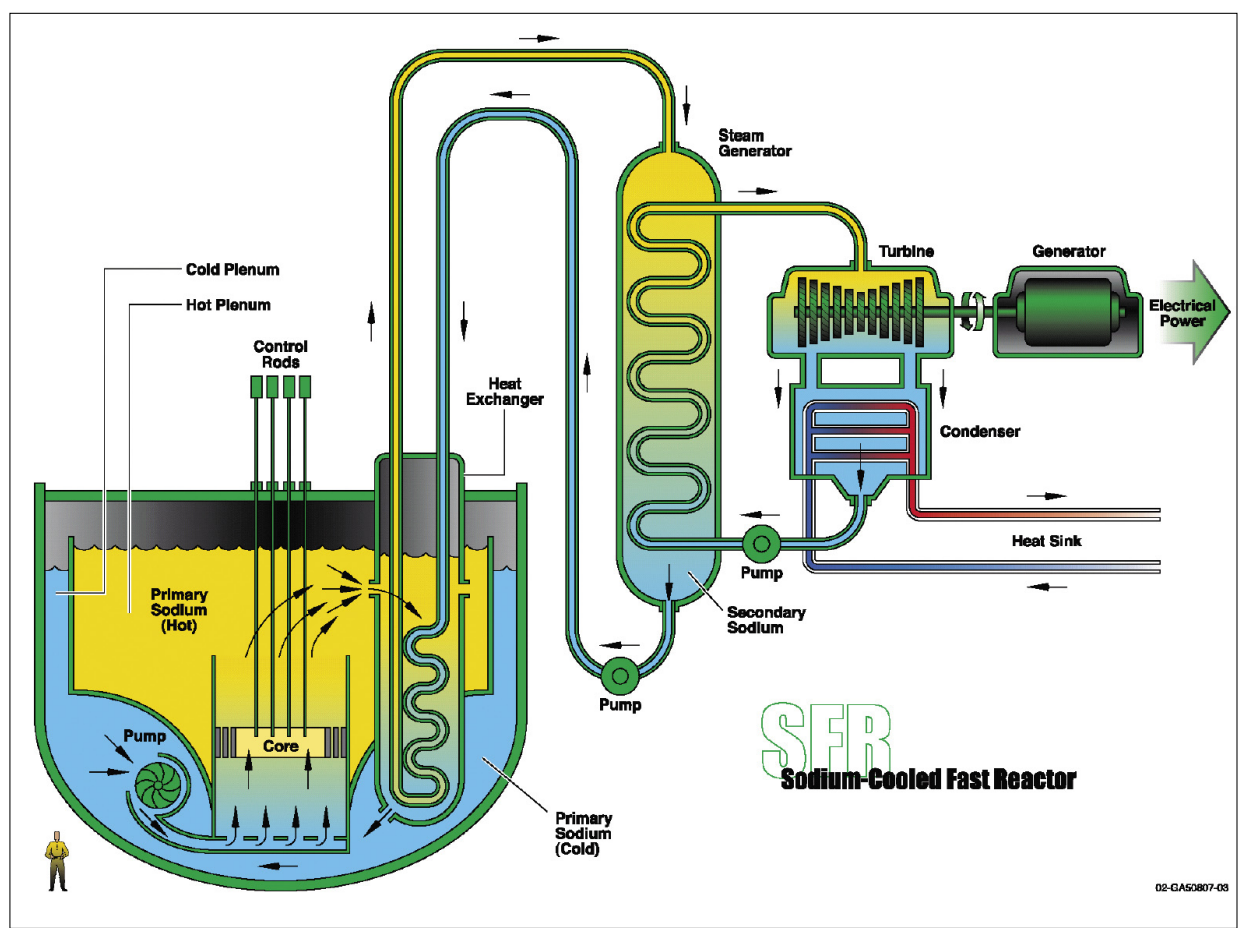

Fig. 1. Conventional sodium-cooled fast reactor (SFR). In the pool system, the reactor core, the primary pumps and the intermediate heat exchangers are housed completely in the reactor vessel. All penetrations are from the top.

content of the liquid metal in the permitted band.

As to activation properties, both sodium and $\mathrm{Pb}-\mathrm{Bi}$ pose some problems: Whereas ${ }^{23} \mathrm{Na}$ absorbs neutrons to form ${ }^{24} \mathrm{Na}$, with a $15 \mathrm{~h}$ half-life, and ${ }^{22} \mathrm{Na}$, with a 2.6 y halflife, neutron capture in ${ }^{209} \mathrm{Bi}$ produces the alpha emitter ${ }^{210} \mathrm{Po}$, with a $138 \mathrm{~d}$ half-life, which is volatile and hence becomes a radiological hazard in the event of a coolant leakage. In the neutron spectrum of a critical fast reactor, lead is not activated, but forms longer lived spallation products when used in an accelerator-driven system (ADS).

\section{Design Concepts and Structural Materials}

\subsection{Principal Design Concepts}

To improve safety, liquid metal cooled reactors, especially sodium-cooled reactors, are usually provided with a secondary or intermediate cooling system which acts as a buffer between the primary system and the steam system. Since the secondary coolant is not activated, a leak in the steam generator cannot lead to a radioactivity release. On the other hand, a secondary cooling system imposes an economic penalty on the plant. Therefore, there is an incentive to develop reactor types which do not require a secondary cooling system.

Two principal design concepts for the cooling system of liquid metal cooled reactors are used: the loop and the pool concept. In the more conventional loop concept, the primary pumps and the intermediate heat exchangers are located outside the reactor vessel and are interconnected with pipes. In a loop system, each loop consists of a single primary and secondary pump and one or more intermediate heat exchangers and steam generators. In contrast, in the pool system all primary system components, i.e. the reactor core, the primary pumps and the intermediate heat exchangers, are housed completely in the reactor vessel (Fig. 1). As in the loop-type reactor, the pool-type reactor may have several 'loops', each consisting of one primary pump and one or more intermediate heat exchangers. Both design 
Table 3. Advantages of the loop and the pool concept

\begin{tabular}{|c|c|c|}
\hline & Advantages of the loop concept & Advantages of the pool concept \\
\hline 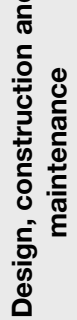 & $\begin{array}{l}\text { - The reactor vessel is smaller. } \\
\text { - The vessel head is simpler. } \\
\text { - The shielding of the secondary } \\
\text { coolant against neutron activation is } \\
\text { simpler. } \\
\text { - The maintenance, inspection and } \\
\text { repair of the primary circuit is simpler. }\end{array}$ & $\begin{array}{l}\text { - The reactor vessel has a simpler } \\
\text { geometry (no tube penetrations). } \\
\text { - The reactor vessel is not in contact with } \\
\text { hot coolant. } \\
\text { - The cover gas system is simpler (the only } \\
\text { free surface is the free surface in the } \\
\text { pool). } \\
\text { - Irradiated fuel can be stored in the } \\
\text { reactor vessel. }\end{array}$ \\
\hline 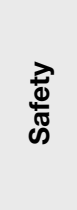 & $\begin{array}{l}\text { - The natural circulation in the primary } \\
\text { circuit can be enhanced by increasing } \\
\text { the elevation of the intermediate heat } \\
\text { exchanger relative to the core. } \\
\text { - The inventory of radioactive coolant is } \\
\text { about three times smaller. }\end{array}$ & $\begin{array}{l}\text { - The probability of a leak in the primary } \\
\text { circuit is much reduced (a loss-of-coolant } \\
\text { accident can be excluded). } \\
\text { - The larger inventory of the primary } \\
\text { coolant results in lower temperature rises } \\
\text { in off-normal situations. }\end{array}$ \\
\hline
\end{tabular}

concepts have advantages and drawbacks (Table 3). On the whole, the advantages and the drawbacks balance each other, meaning that the final choice of the concept may depend on country- and site-specific factors.

\subsection{Structural Materials}

The conditions in the core of a liquid metal cooled fast reactor are more severe than those in a thermal reactor core. In particular, fast reactor structural materials have to withstand a much higher neutron flux, a harder neutron spectrum, a higher coolant temperature, a higher power density, and a higher radiation exposure. The structural components of the primary circuit (reactor vessel, intermediate heat exchangers, primary piping, etc.) operate at elevated temperatures for long periods of time, requiring thermal stress and creep phenomena to be taken into account in the design. In addition, cyclic thermal stress occurs during transient operation (startup and shutdown) and, to some extent, also during steady-state operation (e.g. due to fluctuating temperature fields in the hot coolant pool driven by nonuniform subassembly outlet temperatures). The complex stress conditions, in combination with the irradiation, can result, if not controlled, in severe material damage.

Safety-relevant components which operate at high temperature (e.g. the main vessel of a pool-type reactor) are generally fabricated from austenitic steel. Components which operate at lower temperature (e.g. 'cold-leg' piping) can also be fabricated from other types of steel. The selection of suitable materials for the cladding of the fuel pins and the ducts of the subassemblies poses even more demanding optimisation problems because it involves additional parameters, e.g. the swelling of the materials causing geometrical distortion, the mechanical interaction between the fuel and the cladding and, not least, the ease of fabrication and welding. The experience with sodium-cooled reactors indicates that ferritic-martensitic claddings offer the best compromise. Heat exchangers between liquid metals and steam (steam generators, superheaters) pose also challenging material problems; for the prototype reactors, they were fabricated from both ferritic and austenitic steels, with variable success.

It should be noted that the described optimisations have been performed for sodium-cooled systems which profit from the good compatibility of the sodium with steel. In the newly-proposed heavy metal cooled systems, erosion and corrosion phenomena further complicate the material choices. As the material technology experience base for heavy metal cooled systems is small, it can be expected that large R\&D efforts will be required for re-optimising the material choices for these systems.

\section{Current Development Trends}

\subsection{Overview}

The long-term vision of a sustainable, 'radiologically clean' nuclear energy system is an important driver for the development of advanced reactors and fuel cycles. 'Generation IV' (Gen IV) fast reactors with fully closed fuel cycles [6] will allow the uranium demand and the transuranic (TRU) waste [7] to be reduced by more than two orders of magnitude, compared with the current LWR once-through technology. This means that the systems can utilise the uranium resources also in the highest price categories and the generated high-level waste is practically free of actinides and, in particular, the long-lived species. The systems will achieve these performances while responding to other challenging goals in the areas of safety, reliability and economics.

However, such advanced systems cannot be introduced in a single step. Recognising that the current concern about nu- clear energy relates more to the radioactive waste than to the uranium utilisation, it may be appropriate to consider intermediate scenarios in which the existing LWRs operate in symbiosis with advanced reactors with a dedicated waste burning function. In fact, most fast reactors can easily be converted from breeders to actinide burners.

To enhance the performance of actinide burners, it has been suggested that they are operated as subcritical, accelerator-driven systems. The subcriticality provides additional flexibility in the choice of fuels and can compensate for the unfavourable safety characteristics of some of these fuels. The concept implies the coupling of the reactor with a spallation target [8] which is usually liquid metal cooled. A heavy liquid metal is chosen to enhance the neutron output of the target. The relevance for the ADS target cooling provided an additional incentive for the re-evaluation of liquid heavy metals as reactor coolants.

While advanced nuclear systems were given repeated attention at various stages of the nuclear development, more thorough investigations, with emphasis on actinide and fission product transmutation, began some 15 years ago, first within the OMEGA project in Japan, and later within similar projects in France and the USA. The current 'Technology Roadmap for Generation IV Nuclear Energy Systems', supported by the USA and the 'Generation IV International Forum' (GIF) [9], is particularly suited as a framework for overviewing the current trends in the development of liquid metal cooled reactors.

The liquid metal cooled fast reactor concepts selected by GIF for further evaluation are the Sodium-Cooled Fast Reactor (SFR) and the Lead-Cooled Fast Reactor (LFR). The LFR is cooled by lead or Pb-Bi. The systems are destined for medium-term deployment from about 2015 (SFR) to 2025 (LFR). Different plant sizes are considered, and all variants can operate with fully closed fuel cycles. It should be noted that the GIF evaluates a Gas-Cooled Fast Reactor (GFR) as an alternative to the liquid metal cooled systems [10]. In addition, the GIF considers fast neutron spectrum options for the Molten Salt Reactor (MSR) and the Supercritical-Water Cooled Reactor (SCWR).

Table 4 overviews the SFR and the LFR concepts with regard to the mission of the reactors and the most important reactor parameters. While the SFR takes up the traditional concepts for large, monolithic sodium-cooled reactors, the LFR provides scope for many innovations.

\subsection{Sodium-Cooled Fast Reactors}

The sodium-cooled concepts can be divided into large monolithic and modular concepts. The fuel is in the form of either MOX or a mixed actinide-zirconium metal 
Table 4. Mission and principal parameters for Gen IV liquid metal cooled reactors

\section{SFR}

Plant size

Core outlet

temperature

Mission

- Electricity production

- Plutonium management

- Waste burning as an option

Coolant system configuration

Pool or loop with intermediate coolant circuit

Fuel

Oxide with aqueous reprocessing or metal alloy (Ac-Zr) with pyro-

chemical reprocessing

Structural materials Ferritic-martensitic cladding

\section{LFR}

- Small (50-150 MWe)
- Medium (300-400 MWe)
- Large (1200 MWe)

$550-800{ }^{\circ} \mathrm{C}$
- Electricity production for small and large grids

- Waste burning

- Potable water

- Production of hydrogen and process heat (longer term)

Innovative configurations without intermediate coolant circuit, natural circulation capability, etc.

Metal alloy or nitride

Ferritic cladding (near term), high temperature materials (far term) alloy. The former has the advantage that it can rely on the extensive experience with this fuel in existing reactors. The latter is advantageous if the plant is targeted not only at electricity production, but also at waste management, i.e. actinide burning.

\subsubsection{Large Monolithic Concepts}

Three of the submitted concepts are large monolithic concepts with a power of 1500 MWe. These are the Japanese JSFR, the French RNR 1500 and the British Compact Pool Fast Reactor (CPFR), submitted by JNC, CEA and NNC Ltd respectively. While the JSFR is a loop-type reactor based on the experience with JOYO (100 MWt) and MONJU (300 MWe), the RNR 1500 and the CPFR are pool-type reactors in the line of Superphénix and the European Fast Reactor (EFR) [11]. The concept of the large, pooltype plant is illustrated in Fig. 1.

Although they are based on conventional fast reactor technology, the systems include innovations such as simplified and compact design, new safety features, and increased fuel flexibility which allows their mission (breeder or burner) to be adjusted according to the demand. The concepts are attractive because they fulfil most of the Gen IV sustainability goals while entailing only a minimum R\&D risk. Weaknesses are that recriticality will likely remain a safety and licensing issue and it is still uncertain whether this type of fast reactor will be economically competitive.

\subsubsection{Modular Concepts}

The modular concepts generally represent the technology directions advocated by Argonne National Laboratory (ANL) in its Integral Fast Reactor programme. A particular motivation in this programme was to show from the reactor perspective that the economies of scale, which apply to monolithic plants, can be overcome by changing to modular concepts which are suitable for factory fabrication and easy road and railway transportation. In this context, ANL developed a metal fuel cycle with pyrochemical reprocessing which is economically promising due to its simplicity and compactness and hence allows the collocation of the reprocessing and the modular power plant.

A modular power plant can be composed of several power blocks which, in turn, contain one to three reactors. A good example is the 2280 MWe S-PRISM plant, proposed by General Electric (USA). This plant consists of six 380 MWe reactors arranged in three power blocks. The SPRISM reactor is a pool-type reactor with innovative features such as a fully passive decay heat removal capability. The modular sodium-cooled concepts can also profit from the existing experience base, but entail a somewhat higher development risk than the large monolithic concepts. On the other hand, they may have a greater potential for safety improvements and cost reduction.

\subsubsection{Technology Gaps}

For the SFR, there is an extensive experience base in reactor technology, fuel technology (especially MOX), and reactor safety. SFRs with an electric capacity of $250 \mathrm{MW}$ or more are operating today in Japan (Monju), France (Phénix), and Rus- sia (BN-600). After a fulminate start, the fast reactor development programs in most countries have been slowed down by difficulties with the sodium technology and the high capital cost. A key issue for the SFR is, therefore, the cost reduction. Technology gaps still exist in the areas of:

- The in-service inspection, maintenance, and early detection of abnormal events with special regard to the opacity of the coolant;

- The passively safe response to all transients including transients without scram (control rods do not shut down the reactor on demand) not only for small but also for medium-size and large plants;

- The fuel cycle, demonstrating the actinide burning capability of the SFR in combination with minor actinide loaded oxide fuels reprocessed by advanced PUREX methods as well as the pyroprocess on a larger scale.

\subsection{Lead and Lead-Bismuth Cooled Concepts}

The Gen-IV lead and Pb-Bi cooled concepts span broad ranges in power rating, targeted mission, and innovative design features. Innovations comprise the use of new fuels and materials, unusual core designs, alternative heat transport systems, and new energy converter cycles. The time horizon for the market introduction of these systems depends on the aggressiveness of the innovations. While the nearer-term concepts focus on electricity production, the mid- and long-term concepts seek to exploit the safety potential of lead and to penetrate into the market for high temperature applications such as hydrogen production and process heat. The aggressiveness of the innovation generally increases in the direction from the large monolithic, to the modular, and to the so-called battery concepts. The lead-cooled fast reactor concept shown in Fig. 2 is illustrative for some of these innovations. It features natural convection cooling in the primary circuit at full power and an energy conversion system with a gas turbine.

\subsubsection{Proposed Concepts}

Table 5 summarises the important features of some of the proposed concepts. A well-known example for a large lead cooled concept is the Russian BREST reactor. BREST (1200 MWe) is destined for largescale electricity production and uses nitride fuel which is less well established than oxide or metal fuel. Other unusual features of this reactor are square fuel assemblies (fast reactors traditionally have hexagonal assemblies), a steel-lined concrete reactor vessel, integral steam generators, and a supercritical steam cycle.

The modular concepts are intended to facilitate an incremental capacity addition under the financial conditions of deregulat- 


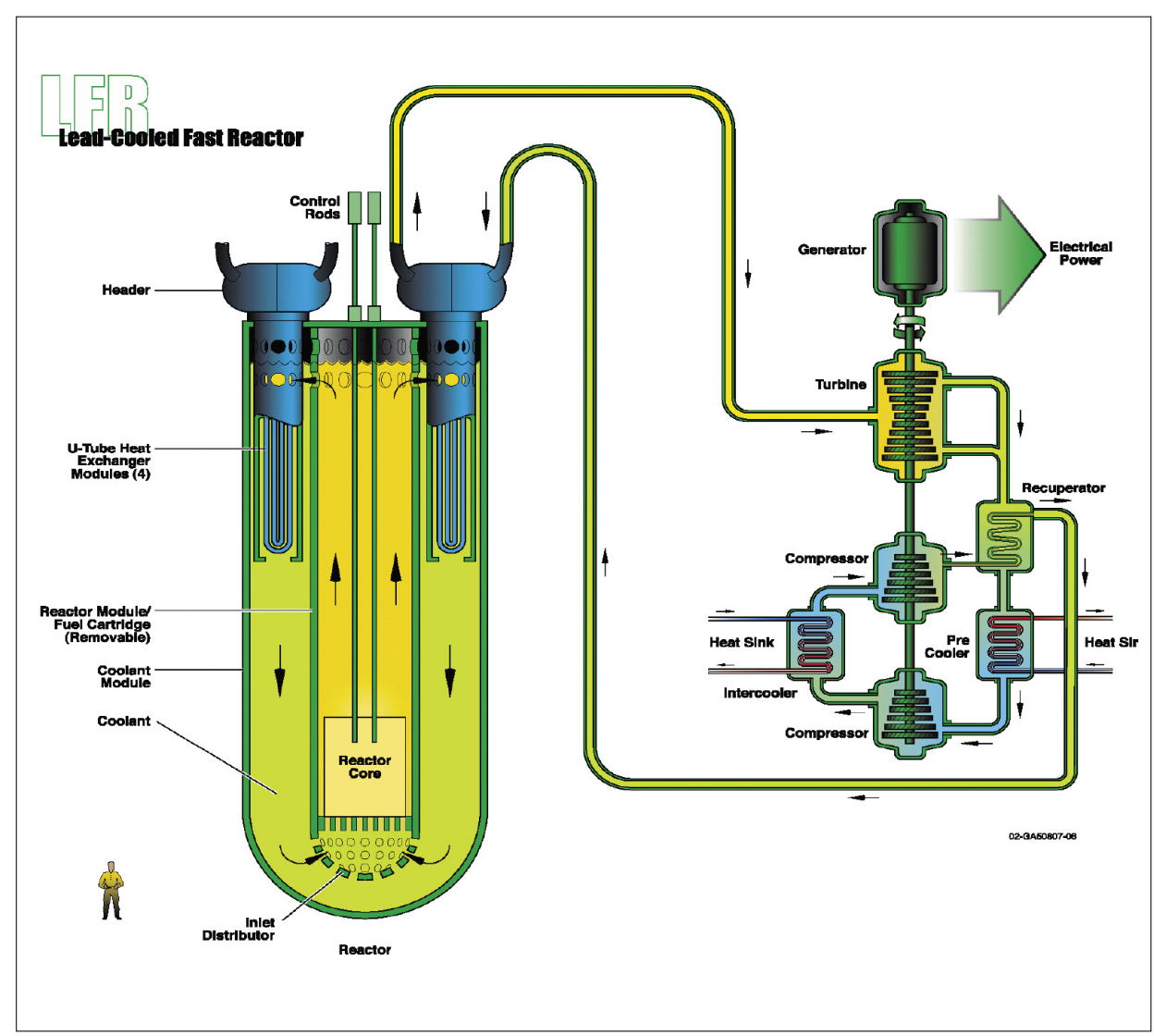

Fig. 2. Gen IV lead-cooled fast reactor. Innovative features are the natural circulation of the coolant in the primary circuit at full power and an energy conversion system with a gas turbine.

Table 5. Attributes of Gen IV lead and $\mathrm{Pb}-\mathrm{Bi}$ cooled reactor concepts (choice of concepts)

\begin{tabular}{|c|c|c|c|c|c|}
\hline $\begin{array}{l}\text { Concept } \\
\text { (Proposer) }\end{array}$ & $\begin{array}{l}\text { Power } \\
\text { (MWe) }\end{array}$ & Mission & $\begin{array}{l}\text { Coolant } \\
\left(T_{\text {Outlet }}\right)\end{array}$ & Fuel & Innovative features \\
\hline \multicolumn{6}{|c|}{ Large monolithic concepts } \\
\hline $\begin{array}{l}\text { BREST } \\
\text { (RDIPE) }\end{array}$ & 1200 & Large scale power production & $\begin{array}{l}\mathrm{Pb} \\
\left(540^{\circ} \mathrm{C}\right)\end{array}$ & Nitride & $\begin{array}{l}\text { - Integral steam generators } \\
\text { - Supercritical steam cycle } \\
\text { - Steel-lined concrete vessel }\end{array}$ \\
\hline \multicolumn{6}{|c|}{ Modular concepts } \\
\hline $\begin{array}{l}\text { RBEC } \\
\text { (Kurchatov) }\end{array}$ & 340 & $\begin{array}{l}\text { Breeding of fissile material for } \\
\text { symbiotic power parks }\end{array}$ & $\mathrm{Pb}-\mathrm{Bi}$ & $\begin{array}{l}\text { Oxide } \\
\text { Carbide }\end{array}$ & Based on proven Russian technology \\
\hline $\begin{array}{l}\text { "M19/M23"- } \\
\text { INEEL/MIT }\end{array}$ & $\sim 400$ & $\begin{array}{l}\text { TRU burning in symbiotic power } \\
\text { parks }\end{array}$ & $\begin{array}{l}\mathrm{Pb}-\mathrm{Bi} \\
\left(540^{\circ} \mathrm{C}\right)\end{array}$ & $\mathrm{Ac}-\mathrm{Zr}$ & $\begin{array}{l}\text { - Integral steam generator } \\
\text { - Square fuel assemblies with streaming } \\
\text { - Fuel with high minor actinide content }\end{array}$ \\
\hline $\begin{array}{l}\text { Option on } \\
\text { "M19/M23" }\end{array}$ & Same & Same & Same & Same & $\begin{array}{l}\text { - Pebble bed fuel } \\
\text { - Downward flow to hold down pebbles }\end{array}$ \\
\hline \multicolumn{6}{|c|}{ Battery concepts } \\
\hline SVK-75/100 & $75-100$ & Near-term battery application & $\begin{array}{l}\mathrm{Pb}-\mathrm{Bi} \\
\left(\sim 500^{\circ} \mathrm{C}\right)\end{array}$ & $\begin{array}{l}\text { Oxide } \\
\text { Nitride }\end{array}$ & Based on Russian submarine technology \\
\hline $\begin{array}{l}\text { STAR-LM } \\
\text { (ANL) }\end{array}$ & $\begin{array}{l}120-160 \\
\text { (thermal) }\end{array}$ & Mid-term battery application & $\begin{array}{l}\text { LBE } \\
\left(\sim 550^{\circ} \mathrm{C}\right)\end{array}$ & $\begin{array}{l}\text { Ac-Zr } \\
\text { Nitride } \\
\text { (pyro) }\end{array}$ & $\begin{array}{l}\text { - Long-life core } \\
\text { - Natural circulation at full power } \\
\text { - Serial factory fabrication }\end{array}$ \\
\hline $\begin{array}{l}\text { STAR-H2 } \\
\text { (ANL) }\end{array}$ & $\begin{array}{l}400 \\
\text { (thermal) }\end{array}$ & $\begin{array}{l}\text { Long-term } \\
\text { high temperature applications } \\
\text { and desalinisation }\end{array}$ & $\begin{array}{l}\mathrm{Pb} \\
\left(780^{\circ} \mathrm{C}\right)\end{array}$ & $\begin{array}{l}\text { Nitride } \\
\text { (pyro) }\end{array}$ & $\begin{array}{l}\text { - Long-life cartrige core } \\
\text { - Lead-helium intermediate heat exchanger }\end{array}$ \\
\hline
\end{tabular}

ed markets. In the nearer term, the Russian $\mathrm{RBEC}$ reactor, with a breeding ratio of about 1.45 , could serve as a factory for fissile material to support the fuel needs of a thermal reactor park. In a similar symbiosis, the more advanced INEEL/MIT concepts could burn the transuranics produced by a thermal park. The proposers think that these concepts would be a cost effective alternative to ADSs which have also been proposed for a TRU burning mission.

The INEEL/MIT modular concepts include various innovations, e.g. a pebble bed core with downward flow which, in the event of a loss-of-flow accident, would passively change from a critical to a subcritical configuration. An interesting option of the concepts is to replace the conventional Rankine steam cycle by a Brayton cycle with supercritical $\mathrm{CO}_{2}$. This would allow a $45 \%$ energy conversion efficiency at the normal $550{ }^{\circ} \mathrm{C} \mathrm{Pb}-\mathrm{Bi}$ outlet temperature and, more important, lead to a considerable reduction in the size and the complexity of the balance of plant installations. Yet another option of these concepts involves a direct contact heat transfer between the $\mathrm{Pb}-\mathrm{Bi}$ and water which is injected in a subcooled state into the hot primary coolant pool above the core. At the pool free surface, the steam and the $\mathrm{Pb}-\mathrm{Bi}$ are separated by gravity and the 
steam is sent to a turbine similar to that of a boiling water reactor.

The category of the battery reactors comprises systems for the near term, the mid term and the longer term. The SVK$75 / 100$ is a civil version of the Russian submarine reactor. It benefits from an industrial final design and the practical experience with this design. The mid-term STAR-LM concept is designed to meet market opportunities for smaller-scale energy production and for developing countries which may not wish to deploy a complete nuclear energy system. Its serial factory fabrication, long refuelling interval and full fuel cycle services support can be attractive for these markets. The long-life core in combination with the passive safety features should simplify reactor operation and reduce maintenance cost. Finally, the long-term STAR-H2 concept exploits the potential of lead-cooled systems to enter the market for high-temperature applications and desalinisation.

\subsection{2. $R \& D$ Challenges}

The current technology base for the LFR is related mainly to the Russian Alpha class submarine reactors and the former IFR programme in the USA; it is, therefore, less robust than that for the SFR. Moreover, the concepts which had the highest rankings in the Gen IV evaluation are mostly at a very early development stage and will require many years of basic R\&D before moving to a detailed design. This applies especially to concepts which seek to exploit high temperature applications. The required technology-based R\&D lies in the areas of (list not exclusive):

- Neutronic data and methods, with emphasis on the validation of lead, $\mathrm{Pb}-\mathrm{Bi}$ and minor actinide data in unusual lattice geometries;

- Fuel development, including the compatibility with the cladding and coolant, taking into account chemical, thermal and structural effects;

- Thermal hydraulics, with emphasis on forced and natural convective heat removal from new types of lattices;

- Design strategies for structural components accounting for the high density of the coolant which lets the structures float;

- High-temperature structural materials for the $750-800{ }^{\circ} \mathrm{C}$ temperature range;

- Coolant chemistry control technologies especially for oxygen and ${ }^{210} \mathrm{Po}$;

- The fuel cycle, demonstrating, e.g. fuel recycling (advanced aqueous and pyrochemical reprocessing, remote fabrication) and waste handling on a laboratory scale;

- New types of heat exchangers and energy converters, including hydrogen production technology and heat exchangers for process heat applications;
- New safety strategies, including protection against earthquakes.

\section{Concluding Remarks}

The GIF activities have revived the interest in fast reactors, and liquid metal cooled reactors in particular, as central components of a sustainable nuclear energy system. The proposed concepts range from conventional sodium-cooled systems, which seek to profit from the already existing, large experience base, to very innovative concepts which will require substantial $R \& D$, especially in the area of materials development. As R\&D funding will be limited, it is likely that many of the more extravagant concepts will never leave the state of a 'paper reactor'. Any serious fuel and material development work will, however, depend on the existence of a suitable fast-spectrum test reactor. For Europe, a promising way forward would, therefore, be to construct in the next 10-15 years a medium-sized, modular fast reactor as a replacement for Phénix which will soon be decommissioned. Such a reactor could only be sodium-cooled. The path to a heavy liquid metal or gas-cooled fast prototype reactor will be much longer and involves considerable technological and financial risks. It is at this stage difficult to see which coolant could eventually establish itself as a viable alternative to sodium. The future will tell.

\section{Related Literature}

The role of fast-spectrum systems (fast reactors and ADSs) in closing the nuclear fuel cycle has recently been assessed in a study of the OECD Nuclear Energy Agency in Paris [12]. The study compares the performance of different fuel cycles with respect to important sustainability parameters, overviews the current status of the fast reactor and ADS technology, and summarises the R\&D needs. Brief histories of the fast reactor and the actinide and fission product transmutation technologies may also be of interest in the present context. The concept of the Integral Fast Reactor and the respective programme carried out in the USA between 1984 and 1994 is described in [13]. The 'Technology Roadmap for Generation IV Nuclear Energy Systems' [14] overviews the Gen IV roadmap project, discusses the evaluation and selection methodology, presents the most promising reactor concepts, and identifies the respective technology gaps. A more detailed description of the proposed lead and $\mathrm{Pb}-\mathrm{Bi}$ cooled systems is given in [15].
[1] C.E. Stevenson, 'The EBR-II Fuel Cycle Story', American Nuclear Society, La Grange Park, Illinois USA (ISBN: 089448-031-6).

[2] The high density of lead and Pb-Bi calls for design measures against floating of the core structures and complicates the seismic design of the plant.

[3] The high melting temperature increases the potential for coolant blockage accidents which can also lead to a whole core accident.

[4] A natural circulation system as principal heat removal system for a large core was first employed by C. Rubbia in his design of an 'Energy Amplifier'.

[5] C. Rubbia, J.A. Rubio, S. Buono, F. Carminati, N. Fiétier, J. Galvez, C. Gelès, Y. Kadi, R. Klapisch, P. Mandrillon, J.P. Revol, C. Roche, 'Conceptual Design of a Fast Neutron Operated High Power Energy Amplifier', CERN/AT/95-44(ET).

[6] In fully closed fuel cycles all actinides are recycled continuously until they are fissioned.

[7] The transuranic actinides are the principal contributors to the radiotoxicity of the high-level waste.

[8] A spallation target, when bombarded with high-energy protons from an accelerator, releases neutrons from spallation reactions in the heavy nuclides of the target.

[9] The GIF countries are Brazil, Canada, France, Japan, the Republic of Korea, the Republic of South Africa, Switzerland, the UK and the USA.

[10] W. Hoffelner, 'Materials for the very High Temperature Reactor (VHTR) a versatile nuclear power station for combined cycle electricity and heat production', Chimia 2005, 59, 977.

[11] The EFR was not submitted to the GIF because the developing company, the European Fast Reactor Utilities Group (EFRUG), stopped the funding of the EFR project in 1993 at the end of the Concept Validation Phase. The EFR, nevertheless, remained a European reference design.

[12] 'Accelerator-driven Systems (ADS) and Fast Reactors (FR) in Advanced Nuclear Fuel Cycles', OECD Nuclear Energy Agency, Paris, 2002, http://www.nea.fr/ html/ndd/reports/2002/nea3109-ads.pdf

[13] 'The Technology of the Integral Fast Reactor and Its Associated Fuel Cycle', Special Issue Progress in Nuclear Energy, Vol. 31, Number 1/2, 1997.

[14] 'A Technology Roadmap for Generation IV Nuclear Energy Systems', U.S. DOE Nuclear Energy Research Advisory Committee and the Generation IV International Forum, GIF-002-00, December 2002.

[15] D.C. Wade, 'The Generation IV Lead Alloy-Cooled Reactor Systems', American Nuclear Energy Symposium, 16-18 October 2002, Miami, Florida, USA. 